\title{
The Empirical Study on the Influences of Depression on the Various Ages of Children and Depression
}

\author{
Niyati Sheokand, Ved Mahla and Priya Arora \\ Department of Psychiatry Shree Guru Gobind Singh Tricentary \\ University, Gurugram, Haryana, India \\ Corresponding author email: niyatisheokand@gmail.com
}

\begin{abstract}
Teenager depression is an undeniable issue. Youngster's depression is normal, ongoing, and intermittent and is related with co-dismal mental condition. So depression forestall youngsters acing significant formative undertaking. The goal of investigation remains to recognize the danger concerns that influencing depression amongst youngster. Aninterdisciplinary examination configuration was utilized to encounter the point of this investigation. The examination was led in auxiliary school. An arbitrary example of 234 students, 124 male and 110 female. Instrument (I) structure talk with poll for socio segment data. Instrument (II) Arabic variant of the multidimensional Childs and adolescentsdepression scale (MCADS). The standard period of considered example was $15.9 \pm 1.24$ year. Huge relationship between teenager's scholastic years, mom'slearningbesides depression. While the all out marks of depression are delegated: great, moderate as well as low $(11.5,78.1 \& 10.4)$ individually. This investigation suggested that, In-management preparing for school medical caretakers and instructors about youngster's depression. Consciousnesssessions for families as peryoungster's depressions.
\end{abstract}

\section{KEY WORDS: BEHAVIOR,DEPRESSION, TEENAGE, YOUNGSTER'S, YOUNGSTER'S DEPRESSION}

\section{INTRODUCTION}

The idea of the 1970s that depression is an affliction of adulthood and that kids and youths don't encounterdepression is currently a distant memory. It has been assessed that depression is the type of psychological sickness influencing the best number of young people (Cash, 2003) with pervasiveness rates between ten; (T. Huberty (2010), R.E. Cash (2020)) furthermore, twenty(A. H. Khalil et. al. (2010)) percent. Seeley, Rohde, Lewinsohn and Clark[4]shown that roughly $28 \%$ of teenagers would encounter a significant depressiondisorder by age 19 . These creators referred to yearly occurrence paces of 1-2\% for kids 13 furthermore, more youthful and $3-7 \%$ for teenagers beginning at age 15 .

Biosc Biotech Res Comm P-ISSN: 0974-6455 E-ISSN: 2321-4007

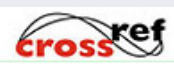

Identifiers and Pagination

Year: 2021 Vol: 14 No (6) Special Issue

Pages: $304-311$

This is an open access article under Creative

Commons License Attribn 4.0 Intl (CC-BY).

DOI: $h t t p: / / d x . d o i . o r g / 10.21786 / b b r c / 14.7 .66$
While they express that the normal beginning period of depression is 15.5 years old they show predominance rates start to increment for females around age 12 and for guys around age 14(J.R. Seeley et. at. (2002).

The lifetime commonness of depression in youngsters gets more prominent as thedepression s age; the lifetime predominance of long term olds, long term olds, and long term olds is $8.4 \%, 12.6 \%$, and $15.4 \%$, individually(K. R. Merikangas et. at. (2010)) The National Institute of Mental Health (n.d.) has detailed measurably noteworthy contrasts across age and gender in the lifetime commonness of state of mind issues, including depression, for young people 13 to 18 . Merikangasfurthermore, (K. R. Merikangas et. at. (2010)) found the lifetime predominance of depression among female young people to be $15.9 \%$ while lifetime commonness for guys was $7.7 \%$.

Depression is more than feeling tragic or down. Depression has been portrayed as "a low, pitiful state in which life appears to be dull and its difficulties overpowering"(R.J. Corner et. al. (2004)), a "genuine medical condition that can influence individuals, " a constant sad or bad tempered

\section{Article Information}

Received: 17th May 2021

Accepted after revision: $24^{\text {th }}$ July 2021 
disposition just as anhedonia, lost the capacity to encounter joy in essentially all exercises"(R.E. CASH et. al. (2004)), and a problem that "influences the whole individual changing the manner in which the person feels, thinks, and acts" (R.E. CASH et. al. (2004)).

These depictions show that depression is more than just being sad; it is a psychological well-being issue that should be paid attention to. The well-established idea that youth is an ordinary season of ill humor and emotionality doesn't precisely portray discouraged youth and the portrayal doesn't demonstrate to others the measure of help these youngsters should manage their depression. Reynolds(W.M. Reynolds et. al. (2004)) expressed that this 'grouchy stage' viewpoint of teenagerdepression can't proceed considering the huge quantities of discouraged and self-destructive youth for whom the result of depression is to not make due to adulthood.

Youth depression, similar to the depression of grownups, can incorporate a range of manifestations going from ordinary reactions of trouble and disillusionment in upsetting life occasions to serious hindrance brought about by clinical depressionthat could possibly incorporate proof of madness(M. Kovacs (1994), E. Weller (1998)). Teenagerdepressioncould influence the depression'scommunal, family relationships, and presentation at school, regularly with possibly genuine long haul outcomes. Young people with depression are in danger for expanded hospitalizations, repetitive miseries, psychosocial impedance, liquor misuse, and reserved practices as they raise up. Obviously, the greatest crushing result of worry for teenagerdepression is self-destruction, the 3rddriving reason for death amongstmore established young people.

Correlational besides longitudinal investigations have demonstrated that depressionremains relatedthrough greater paces of smoking, liquor misuse, undesirable consumption, and rare workout(L.M. Haarasilta (2004), D.L. Franko (2005)). No ideal depression screening/evaluation device exists, however, various teenagerdepression evaluation instruments do have sufficient psychometric properties to complement their utilization in depression discovery and appraisal. Ideal demonstrative strategies ought to consolidate the utilization of depression explicit screening instruments as demonstrative guides bolstered by subsequent clinical meetings in which one acquires data from different sources (e.g., guardians) and accommodates discrepant data to show up at an exact conclusion and debilitation evaluation prior to treatment.

Discouraged people feel caring, edge-like, unhappy, miserable, stressed, insecure, unnecessary, guilty, frightening or grievous. You can lose interest for activities until amusing, have issues concentrating, recollecting subtleties, or deciding, and may consider, endeavor, or end it all. Depressioncan likewise present as substantial aggravations like Sleep deprivation, inordinate resting, exhaustion, loss of energy, or then again hurts, torments, or stomach related issues that are impervious to treatment may likewise be present(P.M. Lewinsohn et. al. (2004)). The socio-segment variables old enough, gender orientation, instruction and pay have been recognized as significant factors in clarifying the fluctuation in the pervasiveness of depression(The National Institute of Mental Health et. al. (2004)).About 11\% of teenager have a depression problem by age 18 as indicated by National Co-morbidly Survey-Depression Supplement (NCS-A). Depression is more in young ladies depression than young men(R.C. Kessler et. al. (1994)). Money et al. discovered that up to $60 \%$ of teenagersuicidecasualties experienced depression at the hour of death.

Genuine depression in youngsters is regularly hard to analyze on the grounds that ordinary teenagerbehavior is set apart by both all over states of mind because of the hormonal changes youngsters experience(D.L. MacKenzie et. al. (2001)). Family factors what's more, the social setting could assume a significant part improving depression; literally the factors that go beyond one's reach that emerge as a frightful chance inside the day by day climate, and that repeat after some time. inspected the social and segment factors that are altogether connected with more elevated levels of depression side effects, three elements were found with factually critical relationship with more extreme levels of depression side effects.

These elements included: the degree of financial satisfaction, the degree of affection with caregivers as well as the degree of close proximity with colleagues(M.B.D YAPet. al. (2014)). Recognize that Parental variables through a solid proof founded demonstrating expanded danger for equallyunhappiness and uneasiness incorporate less temperateness, more between parental clash, overassociation, and shiftiness, as well astodepression also, they incorporate less self-sufficiency allowing and checking. Mehler-Wex and Kölch(C. Mehler-Wex et. al. (2008)) likewise included that depression indications in minors are firmly subject to their age. Table 1, displays diverse age bunches through their comparing psychopathology and physical signs.

Teenager significant depression issue and dysthymic problem are normal, persistent, familial, and repetitive conditions that typically persevere into adulthood. These issues seem, by all accounts, to be showing at a previous age in progressive associates and are generally joined by co-sullen mental problems, expanded danger for suicide, substance misuse, and behavior issues. Also, discouraged youth every now and again have deprived psychosocial, scholarly, and families workingthat features the significance of early cure. Youngsters amongst the aged 15 towards 24 speak to $22.54 \%$ of all out populace(M. Biltagy et. al. (2014)). This enormous and developing gathering faces issues and difficulties that are special to them besides that necessitateintercessions and data that discourse their necessities. Depression remains a period of huge bodily, enthusiastic, social, gender and mental change. So the examination directed to recognize the danger factors that influencing depression among depressions.

\section{Research Questions}

1. The factors of depression that are affecting the youngsters and children mentally and physically? 
2. Why the youngsters committing suicide cause of the depression?

\section{Literature Review}

Occurrence of Child and Teen-age Depression: The event of depression and self-destructive behavior happens prior throughout everyday life than it was 50 years back(K Murohy et. al. (2004)). As indicated by NIMH 2007; U.S. General Health Service 1999; Herman et al. (K.C. Herman et. al. (2009)), 1 in 10 kids is experiencing agreat enthusiastic unsettling influence that'sreasons of hindrance. The developing amount of studies affirmed that depression usually and steadily influences youngsters.
The rate significantly increments as youngsters transform into immaturity(J.A. Dopheide et. al. (2006)). Despite the fact that depression throughout youngsters is amongst the greatest weakening mental disorder, "it likewise one the most neglected and undertreated ailment"(K.C. Herman et. al. (2009)). With the high number of youngsters and teenagers experiencing despondency, up to $80 \%$ of them are not given any type of treatment(P.M. Lewinsohn et. al. (1998)). Despondency influenced $0.3 \%$ of preschoolers, $2 \%$ of primary young kids, as well as $5-10 \%$ of teenagers. Pre-puberty deponents are comparable and accumulated in women after childhood. young males and young women (J.A. Dopheide et. al. (2006).

\begin{tabular}{|c|c|}
\hline Age Group & Symptoms (psychopathological) \\
\hline Children & 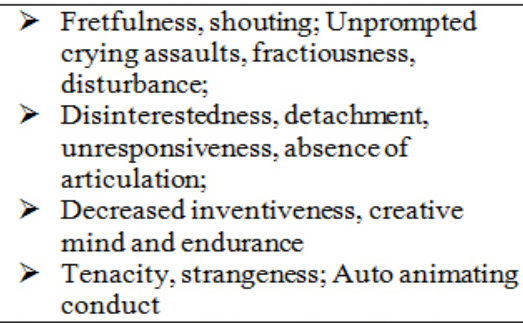 \\
\hline Preschool children & $\begin{aligned} &> \text { Crying, touchiness, forceful and } \\
& \text { hazardous episodes, }\end{aligned}$ \\
\hline School children & $\begin{aligned} &> \text { Crying, rebellious conduct, safeguard, } \\
& \text { forceful practices; } \\
&>\text { Self-detailed pity, languor and absence } \\
& \text { of drive, Disinterestedness, } \\
& \text { withdrawal; Problems concentrating, } \\
& \text { disappointment at school } \\
&>\text { Stresses, introductory contemplations } \\
& \text { communicating sluggishness of life; } \\
& \text { Attention chasing }\end{aligned}$ \\
\hline Teenager & $\begin{array}{l}\text { Detachment, desolation, denial, } \\
\text { absence of ambition, disinterestedness, } \\
\text { removal; } \\
\text { Musings and activities eased back } \\
\text { down, issues in } \\
\text { execution/accomplishments, } \\
\text { intellectual impedances; } \\
>\text { Uneasiness, nauseate, absence of self- } \\
\text { assurance, self-severity, agonizing, } \\
\text { dread of things to come, suicidality }\end{array}$ \\
\hline
\end{tabular}

In a Finnish report by Fröjd et al. (S. Fröjd et. al. (2007)), that included the objective gathering of seventh - 9th grade students matured 13-17 years going to optional schools in Pori, pace of melancholy was discovered to be at $18.4 \%$ amongst young ladies besides $11.1 \%$ amongstyoung men. Melancholy was estimated utilizing R-Beck Depression List (BDL) thatremains the Finnish adjustment of the 13-assets rendition of BDL. Other different examination in 2 locales of Finland (Vaasa district besidesPirkanmaa) comprised of students with auxiliary schools of eighth and ninth standard, exposedanaltogether-out consequence of $17.2 \%$ students have in any event gentle melancholy. The prevalence of mild sadness amongst young women has been shown to be $11.2 \%$ and 5.9\% amongst youths. Moderate sadness has been shown to be $9.0 \%$ amongst young people and $4.7 \%$ amongst young males, while severe suffering amongst young males and women has been discoveredto be $2.1 \%$ besides $1.5 \%$, individually(R. Kaltiala-Heino et. al. (2000). 
An ongoing Finnish analytic meeting based investigations which was led in all-inclusive community indicated a comparing paces of juvenile despondency scope of $0.9 \%$ to $7.8 \%$ contingent upon time span(R. Kaltiala-Heino (2007), T. Aalto- SETÄLÄ (2001)). Moreover, late Finnish rating scale based investigations assessed juvenile sorrow from $6 \%$ to $14 \%$ (S. Fröjd (2007), R. Kaltiala-Heino (2007)). With regards to Finland, there is no proof of immense increment in paces of depression indications among the young people(M. Ritakallio et. al. (2008)) yet there may have been some expansion in the depression paces of kids in the previous many years(M. Ritakallio et. al. (2008)).

As per Maharajh et al(H.D. Maharajh et. al. (2006)), In different nations and cultures, the basic speed of youthful sadness has shifted. In high schoolers aged 16 and 17 years old, a depression of 12.3 percent was observed in Sweden(H.D. Maharajh et. al. (2006)). Though throughout Italy, a reduced pace $3.8 \%$ was exposed. Canadian and British(H.D. Maharajh et. al. (2006)) The comparable levels of depression produced by young people was $10 \%$. Different inquiries into young Chinese individual reported a ranking of $13 \%$ respectively $11 \%$, with Australian younger folks reported a rating of $14.2 \%$. A rising incidence of $35,1 \%$ youth melancholy was observed in Guatemala(H.D. Maharajh et. al. (2006)). Throughout Western Europe, Asia as well as Australia, lower rates were recorded.

Side effects of Children by Depression: The side effects of despondency can shift through age(B. Birmaher (1996), J.A. Dopheide (2006)). As noted from past accessible literary works, the indications of sorrow in young youngsters, young people, and grown-ups are comparative, with to some degree increment in the recurrence in young people than in youngsters in the sign of depression and a few vegetative and persuasive indications (G.A. Carlson et. al. (1988)). Indications of specific depression manifestations can likewise shift through the youngster'sstage of psychological as well as social advancement. In medical introduction, this was approved that long term old kids have been determined to have significant depression problem(J.A. Dopeide et. al. (2006).

In any case, precise explores on despondency in preyoung and babies are restricted; consequently, presence of conditions showed in young youngsters, teenagers, and grown-ups are muddled in exceptionally small kids(D.N. Klein et. al. (2005)). Contingent upon the seriousness ofdepression, depression turmoil may likewise be joined by maniacal manifestations. In minors, such insane indications are generally showed by a sentiment of evil, blame, or disappointment(C. Mehler-Wex et. al. (2008). In the manuscriptIdentifying Depression via Kathryn Murphy(K. Murphy et. al. (2004)), the primary sign of despondency in little youngsters remains anhedonia - the absence important to take part in agreeable exercises. Tenacious shows of self-destructive or reckless subject in plays showed by preschoolers, or a truly solid kid showing boredoms in play are model indications of anhedonia(J.A. Dopheide et. al. (2006)). Some formative assignments of young people can be reached by playing, but the existence of anhedonia does not involvement of the teenager, subsequently impede advancements(K. Murphy et. al. (2004)).

Perceiving depression manifestations in kid's age 8 and more youthful may not be simple since they are less inclined to express their feelings and rather show manifestations of tension (for example fears, division nervousness), physical whines, and hear-able fantasies(J.A. Dopheide et. al. (2006))... Substantial objection, for example, discontinuous stomach torment is regularly found in essential care workplaces(K. Murphy et. al. (2004)). Discouraged kids likewise cluster indications of touchiness, fits, and other social issues. Youngsters ages 9- 12 years and are discouraged may discuss fleeing, giving indications of fatigue, offense, or depression, absence of confidence, and dread of death. In contrast to teenagers with wretchedness, youngsters are more averse to encounter fancy or make genuine consideration to end it all(J.A. Dopheide (2006), B. Birmaher (1996).

There were just scarcely any examinations directed to analyze the gender related depressionmore adolescent school youth protests. In one analysis a case was investigated for gender orientation in the instance of 122 kids of 6 th and 7 th grades from four rural working groups. in depression side effects through the usage of kid's Depression List (CDL) (M.K. Bailey et. al. (2007)). The observations suggested that younger women were more veiled and negatively worried with themselves, while teenage boys were outsourced with more intellectual concerns. While depression levels are typically considerably higher for young women than for teenage boys in the CDL, that issue was still regarded as negligible(M.K. Bailey et. al. (2007). Moreover, indications of sorrow can likewise be comparative with different issues in kids. Therefore, precise determination is essential to effectively destroy the disease. Sorrow brought about by dysfunctional behavior and clinical condition must be appropriately separated(K. Murphy et. al. (2004).

Manifestations of Depression s with Depression: Youth is a crucial season of improvement and it connotes a time of higherhazard for depression. Onsuch phase of improvement, depression indications are regularly excused or overlooked as indications of youthfulness or high school practices. Any irregular or surprising behavior appeared through them are frequently connected to the "temporary phase" that kids are experiencing or incidental terrible temperament overthan experiencing depression. Discouraged temperament has had been alluded as a regular understand during puberty. The pre-teenage ageddepression rates for young men besides young ladies are comparable, and multiplied in woman'safterward adolescence(J.A. Dopheide (2006), B. Birmaher (1996)). Woman's are on anadvanced danger of $1 \mathrm{st}$ beginning of significant depressionsinceinitial immaturity till their middle-50s besides have a generation melancholy pace of 1.7 towards 2.7 overlap more prominent over guys. Research's announced that young ladies are additional discouraged what's more, more seriously discouraged than young men(M. Crowe et. al. (2006). 


\section{METHODOLOGY}

This research was carried out in Govt high schools as well as the interviewees were randomly chosen from schools.

Research Design: A cross-sectional analysis architecture has been used to achieve the purpose of the investigation and also to evaluate the causes of the depression.

Sample: An arbitrary example of 234students, 124 male and 110women. This wouldshield the insignificant mandatory example scope of $22 \mathrm{f} 5$ students dependent on expected predominance of depression amongst youths $=20.5 \%$ throughaexactness of 7\% and certainty level of $93 \%$.

Instrument: Device (I) organized meeting survey for socio-segment statistics. Instrument (II) Arabic rendition of the MCADS.

Data Collection: The data collectioninstrument was intended to characterize the outline of youngster's depression. There are eight scales, with five declarations examining each calculation, the MCADS includes 40 short papers as follows: Pessimism: spoken of by 1-5 examples, Poor focus: talked by 5-19 examples, Sleep problems: spoke to by explanations towards 10-14, Anhedonia: spoke to by explanations towards 15-19, Exhaustion: spoke to by articulations towards 20-24, Aloneness: spoke to by explanations towards 25-29, Lower confidence: spoke to by articulations from 30-34, Somatic grumblings: spoke to by proclamations from 35-39. A triple rating scales of the Likert sort was used to assess the depressive strength of None $=1$, occasionally $=2, \mathrm{~A}$ lot $=3$., aside from proclamations $1,5,10$, $15,22,33$, and 34 which were scored as follows: non as 3 , some of the time as 2 and a great deal as 1 . Everything ought to be replied by choosing just one of the three other options, which generally depicts the enthusiastic condition of the students. Concerning the dependability from the size of the measure, Cronbach alpha goes between 0.62 to 0.91 , unwavering quality ran somewhere in the range of 0.55 and 0.86 . As to, measure related legitimacy went somewhere in the range of 0.29 and 0.84 .

Data Analysis: The pilot investigation was completed on $10 \%$ subjects were not permitted to pass the assessment test to ensure the stability of the responses. They were picked to examination the lucidity and pertinence of the apparatus utilized, at that point important change was finished by the aftereffects of pilot study and ability sentiments. The genuine investigation was led 2 days each week between February and May 2013. Each student is packed with the appliances for 15-20 minutes. Assortment of information was proceeded as the accompanying: the specialists acquired an authorized consent of overseers of institutes in the wake of clarifying the reason for the examination and how it will be completed.

An authorized consent was acquired through accommodation an authorized communication from its school supervisors to the eligible test specialists to get the approval for information assortment. The point of examination was disclosed to understudies earlier investment, intentional cooperation was accentuated as well asaverbal assent was gotten. Guaranteed those acquired data will going to be secret and utilized uniquely with the end goal of the examination. Information were examined utilizing measurable bundle for sociologies (SPSS 18).

The P-esteem $<0.05$ remained utilized as the end an incentive for measurable centrality. As to scale; complete score for every area was determined by adding the discrete scores for its things, at by dividing the points value by 100 the smallest score on the largest score was decided. The score percentage at this level shifted into a lower sorrow score for those with a score less than $50.0 \%$. Mild if the rating percent rose beyond $51.0 \%$ to below $76.0 \%$, and strong melancholy unless the rating percent exceeded $76 \%$. The following factual metrics were used: average and standard deviations were used for details on size. The t-test of students was used for analyzing mean sadness. To identify the key hazard factors that contribute to melancholy, Spearman coefficients and strategic rebound were used to convey the degree of effects, using separate proportions of possibilities for each cause.

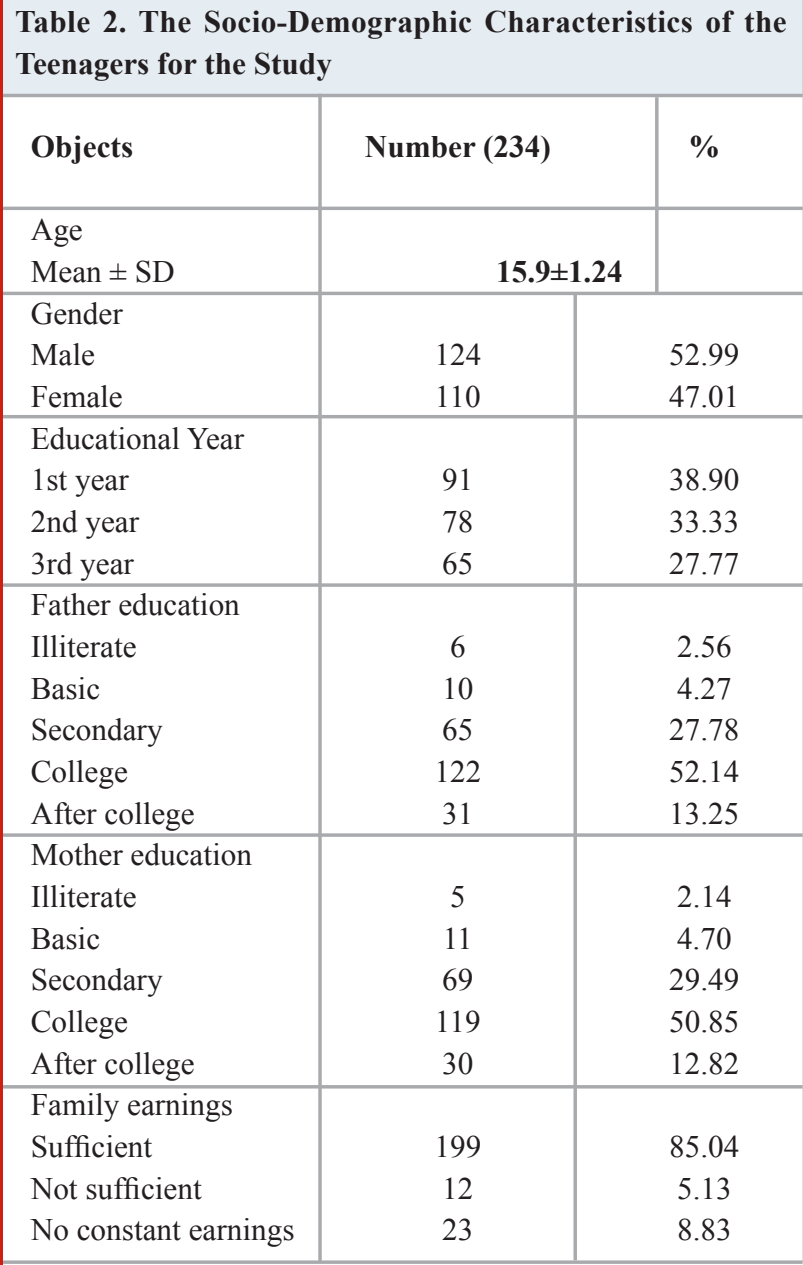

RESULTS

Table (2) delineates the segment information amongst the contemplated test. The outcomes uncover that mean period of examined test was $15.9 \pm 1.24$ year. The greater part of 
the contemplated test $(52.99 \%)$ was males. As respects dispersion of the contemplated test founded of scholarly years, it may beseen that, $38.90 \%$ of the examined test were throughout standardone auxiliary, $33.33 \%$ were throughout standardtwo optional and $27.77 \%$ were throughout standard three optional. Talking according to parent's instruction the greater part of the guardians $(52.14 \%$ of fathers and $50.85 \%$ of moms) had a college degree. As respect monetary state of the contemplated test most of them (85.04\%) referenced that family' salary was sufficient.

Figure (1) displays that the absolute marks of melancholy stage as per multi-talented kids and young adult wretchedness scales. The most noteworthy all out marks of despondency was (11.5) besides the modest absolute marks of depression remained (78.1), although the least complete marks of depression remained (10.4).

Figure 1: Allocation of Different Teens According To Their Types and Rates of Depression

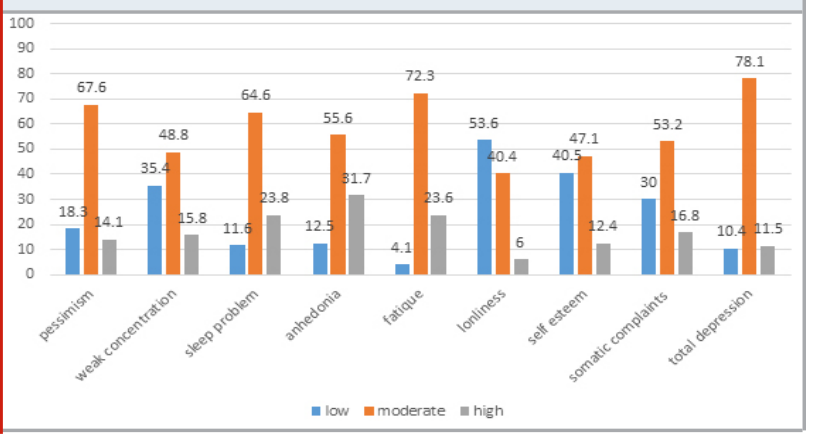

\section{DISCUSSION}

Up to this point, analysts accepted that lone grownups experienced depression. They currently know, notwithstanding, that depression $\mathrm{s}$ and even kids can experience the ill effects of it. At the point when young people are discouraged, they sense pitiful besides self-basic, they additionally accept that someone else are incredulous to them. Discouraged depression s are additional whelmed at settling on even basic choices. They regularly disregard their appearance and may showcase their disappointments in a forceful style(F.P. Rice et. al. (2005)). The aftereffects of this investigation indicated a proximal likeness of standard marks of depression amongstdepression's young men as well as young ladies and this outcomes conflict through who detailed that youngster's young ladies have elevated stageof depressionover high schooler's young men.

The finding of present investigation uncovered that young people depression was higher fundamentally amongst teenagers who are with their parent's essential degree of instruction. It very well may be seen that the more elevated stage of guardians' instruction, the reduced marks of melancholy amongst their youngsters through measurable distinction amongstMother's teaching qualification including depression rating between her depressions. Compatible with the findings of the present study, the depression throughout school problems used to have a high overall depression level. (M. Chen et. al. (2009)).
This concerns the implications of who find that the stress in students who had bad feelings about school but had school difficulties were more common. The weight between parents on their teenagers may be a necessary result of finding the best prices in the inquiry.

The consequences of the current investigation feature the significance of family's function throughout the advancement of teenagerdepressions. The discoveries discovered highermarks of depression amongstsuch youngsters who saw that adoration and helpful are missing inside their relatives, experiencing high abusive behavior at home, and with diminishing of family jumping and resistance. Concerning misuse the current investigation consistent with(J.A. Lehrer et. al. (2006)) who detailed that depression side effects were emphatically connected with substance misuse and revealed the drug use can occur in efforts to improve the mentality of discouraged people, however, a permanent use of substances is feasible to lead to neurobiological alteration which cause depression development weakness.

\section{CONCLUSION}

This investigation presumed that depression remains pervasive in youngsters. Collapse of family connections and inconveniences at schools are related danger features for improvement of adolescentdepressions. This investigation prescribed that extra examinations are expected to check if initial discovery of depression issues in teenagers couldInfluence including challenges of the path of depression. Putting the behavioral guide's position on the classroom, increasing complementary linkage between caregivers and the younger individuals, must also be necessary for persuasive mediations. Further exams on the risk factors associated with adolescence depression. Directed in management for school caregivers and students on depression as well as young adults to assess early symptoms of depression. Family consciousness plans on the alienation of young people.

\section{REFERENCES}

Aalto-Setälä, T., Marttunen, M., Tuulio-Henriksson, A., Poikolainen, K. and Lönnqvist, J., 2001. One-month prevalence of depression and other DSM-IV disorders among young adults. Psychological medicine, 31(5), pp.791-801.

Bailey, M.K., Zauszniewski, J.A., Heinzer, M.M. and Hemstrom $\square$ Krainess, A.M., 2007. Patterns of depressive symptoms in children. Journal of Child and Adolescent Psychiatric Nursing, 20(2), pp.86-95.

Biltagy, M., 2014. Estimation of gender wage differentials in Egypt using Oaxaca decomposition technique. Topics in Middle Eastern and African Economies, 16(1), pp.1742.

Birmaher, B., Ryan, N.D., Williamson, D.E., Brent, D.A., Kaufman, J., Dahl, R.E., Perel, J. and Nelson, B., 1996. Childhood and adolescent depression: a review of the past 
10 years. Part I. Journal of the American Academy of Child \& Adolescent Psychiatry, 35(11), pp.1427-1439.

Carlson, G.A. and Kashani, J.H., 1988. Phenomenology of major depression from childhood through adulthood: analysis of three studies. The American Journal of Psychiatry.

Cash, R.E., 2003. When it hurts to be a teenager. Principal Leadership, 4(2), pp.11-15.

Chen, M., Johnston, C., Sheeber, L. and Leve, C., 2009. Parent and adolescent depressive symptoms: The role of parental attributions. Journal of abnormal child psychology, 37(1), pp.119-130.

Crowe, M., Ward, N., Dunnachie, B. and Roberts, M., 2006. Characteristics of adolescent depression. International journal of mental health nursing, 15(1), pp.10-18.

Dhir, A., Yossatorn, Y., Kaur, P. and Chen, S., 2018. Online social media fatigue and psychological wellbeing-A study of compulsive use, fear of missing out, fatigue, anxiety and depression. International Journal of Information Management, 40, pp.141-152.

Dopheide, J.A., 2006. Recognizing and treating depression in children and adolescents. American journal of healthsystem pharmacy, 63(3), pp.233-243.

Franko, D.L., Striegel-Moore, R.H., Bean, J., Tamer, R., Kraemer, H.C., Dohm, F.A., Crawford, P.B., Schreiber, G. and Daniels, S.R., 2005. Psychosocial and health consequences of adolescent depression in Black and White young adult women. Health Psychology, 24(6), p.586.

Fröjd, S., Kaltiala-Heino, R. and Rimpelä, M., 2007. The association of parental monitoring and family structure with diverse maladjustment outcomes in middle adolescent boys and girls. Nordic Journal of Psychiatry, 61(4), pp.296303.

Haarasilta, L.M., Marttunen, M.J., Kaprio, J.A. and Aro, H.M., 2004. Correlates of depression in a representative nationwide sample of adolescents (15-19 years) and young adults (20-24 years). The European Journal of Public Health, 14(3), pp.280-285.

Kaltiala-Heino, R., Rimpelä, M., Rantanen, P. and Rimpelä, A., 2000. Bullying at school-an indicator of adolescents at risk for mental disorders. Journal of adolescence, 23(6), pp.661-674.

Kessler, R.C., McGonagle, K.A., Zhao, S., Nelson, C.B., Hughes, M., Eshleman, S., Wittchen, H.U. and Kendler, K.S., 1994. Lifetime and 12-month prevalence of DSMIII-R psychiatric disorders in the United States: results from the National Comorbidity Survey. Archives of general psychiatry, 51(1), pp.8-19.

Khalil, A.H., Rabie, M.A., Abd-El-Aziz, M.F., Abdou, T.A., El-Rasheed, A.H. and Sabry, W.M., 2010. Clinical characteristics of depression among adolescent females: a cross-sectional study. Child and adolescent psychiatry and mental health, 4(1), pp.1-7.

Klein, D.N., Dougherty, L.R. and Olino, T.M., 2005. Toward guidelines for evidence-based assessment of depression in children and adolescents. Journal of Clinical Child and Adolescent Psychology, 34(3), pp.412-432.

Kovacs, M., Akiskal, H.S., Gatsonis, C. and Parrone, P.L., 1994. Childhood-onset dysthymic disorder: Clinical features and prospective naturalistic outcome. Archives of general psychiatry, 51(5), pp.365-374.

Lehrer, J.A., Shrier, L.A., Gortmaker, S. and Buka, S., 2006. Depressive symptoms as a longitudinal predictor of sexual risk behaviors among US middle and high school students. Pediatrics, 118(1), pp.189-200.

Lewinsohn, P.M., Gotlib, I.H., Lewinsohn, M., Seeley, J.R. and Allen, N.B., 1998. Gender differences in anxiety disorders and anxiety symptoms in adolescents. Journal of abnormal psychology, 107(1), p.109.

MacKenzie, D.L., Gover, A.R., Armstrong, G.S. and Mitchell, O., 2001. A national study comparing the environments of boot camps with traditional facilities for juvenile offenders. National Institute of Justice Research in Brief.

Maharajh, H.D., Ali, A. and Konings, M., 2006. Adolescent depression in Trinidad and Tobago. European child \& adolescent psychiatry, 15(1), pp.30-37.

Maurizi, L.K., Ceballo, R., Epstein $\square$ Ngo, Q. and Cortina, K.S., 2013. Does neighborhood belonging matter? Examining school and neighborhood belonging as protective factors for Latino adolescents. American Journal of Orthopsychiatry, 83(2-3), p.323.

Mehler-Wex, C. and Kölch, M., 2008. Depressive Störungen im Kindes-und Jugendalter. Deutsches Ärzteblatt, 105(9), pp.149-155.

Merikangas, K.R., He, J.P., Burstein, M., Swanson, S.A., Avenevoli, S., Cui, L., Benjet, C., Georgiades, K. and Swendsen, J., 2010. Lifetime prevalence of mental disorders in US adolescents: results from the National Comorbidity Survey Replication-Adolescent Supplement (NCS-A). Journal of the American Academy of Child \& Adolescent Psychiatry, 49(10), pp.980-989.

Murphy, K., 2004. Recognizing depression in children. The Nurse Practitioner, 29(9), pp.18-29.

Nikolaou, E., Moustakas, L. and Markogiannakis, G., 2017. Greek Teachers' Perceptions on the Effective Strategies and Interventions for Addressing Children with Depression in School Context. Science Journal of Education, 5(4), pp.185-191.

Reynolds, W.M., 1984. Depression in children and adolescents: Phenomenology, evaluation and treatment. School Psychology Review, 13(2), pp.171-182. 
Ritakallio, M., Koivisto, A.M., von der Pahlen, B., Pelkonen, M., Marttunen, M. and Kaltiala-Heino, R., 2008. Continuity, comorbidity and longitudinal associations between depression and antisocial behaviour in middle adolescence: A 2-year prospective follow-up study. Journal of adolescence, 31(3), pp.355-370.

Rice, F.P. and Dolgin, K.G., 2005. The adolescent: Development, relationships and culture. Pearson Education New Zealand.

Rodrigues, V. and Friedman, H.L., 2013. Transpersonal psychotherapies. The Wiley $\square$ Blackwell Handbook of Transpersonal Psychology, pp.580-594.

Seeley, J.R., Rohde, P., Lewinsohn, P.M. and Clarke, G.N., 2002. Depression in youth: Epidemiology, identification, and intervention. Interventions for academic and behavior problems II: Preventive and remedial approaches, pp.885911.
Sihvola, E., Keski-Rahkonen, A., Dick, D.M., Pulkkinen, L., Rose, R.J., Marttunen, M. and Kaprio, J., 2007. Minor depression in adolescence: Phenomenology and clinical correlates. Journal of affective disorders, 97(1-3), pp.211218.

Venkata Pavan, M., Karnan, B. and Latchoumi, T.P., 2021. PLA-Cu reinforced composite filament: Preparation and flexural property printed at different machining conditions. Advanced Composite Materials, https://doi. org/10.1080/09243046.2021, 1918608.

Weller, E., Weller, R.A. and Dogin, J.W., 1998. A rose is a rose is a rose. Journal of affective disorders, 51(2), pp.189-193.

Yap, M.B.H., Pilkington, P.D., Ryan, S.M. and Jorm, A.F., 2014. Parental factors associated with depression and anxiety in young people: A systematic review and metaanalysis. Journal of affective disorders, 156, pp.8-23. 